\title{
Article
}

\section{Object Relations in the Museum: A Psychosocial Perspective}

Froggett, Lynn and Trustram, Myna

Available at http://clok.uclan.ac.uk/10787/

Froggett, Lynn ORCID: 0000-0001-8406-6231 and Trustram, Myna (2014)

Object Relations in the Museum: A Psychosocial Perspective. Museum Management and Curatorship, 29 (5). pp. 482-497. ISSN 0964-7775

It is advisable to refer to the publisher's version if you intend to cite from the work. http://dx.doi.org/10.1080/09647775.2014.957481

For more information about UCLan's research in this area go to

http://www.uclan.ac.uk/researchgroups/ and search for < name of research Group>.

For information about Research generally at UCLan please go to http://www.uclan.ac.uk/research/

All outputs in CLoK are protected by Intellectual Property Rights law, including Copyright law. Copyright, IPR and Moral Rights for the works on this site are retained by the individual authors and/or other copyright owners. Terms and conditions for use of this material are defined in the policies page.

\section{CLoK}

Central Lancashire online Knowledge www.clok.uclan.ac.uk

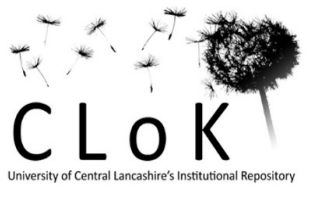


Professor Lynn Froggett, Psychosocial Research Unit, University of Central Lancashire, UK

Dr Myna Trustram, Manchester School of Art, Manchester Metropolitan University, UK

Corresponding author: Myna Trustram, Manchester School of Art, Manchester Metropolitan University, Righton Building, Cavendish Street, Manchester M15 6BG, UK.

Telephone: 01612471118 / 075903 68050. Email: m.trustram@mmu.ac.uk

\section{Author biographies}

Professor Lynn Froggett is Director of the Psychosocial Research Unit at the University of Central Lancashire. She has a cross-disciplinary background in the Humanities and Social Sciences and has researched the Socially Engaged Arts for over a decade. She has a particular interest in developing studies that incorporate both arts-based and social scientific methodologies and she studies the contribution of the arts to health, wellbeing, social justice, civic engagement and citizenship.

Myna Trustram is a Research Associate at Manchester School of Art, Manchester Metropolitan University. She has worked for many years in curatorial, management and research roles within museums and galleries. She has trained with the Tavistock Clinic and the Institute for Group Analysis in the psychodynamics of organizations and groups. Her major project is called 'Museum Melancholy: Loss in the midst of plenty' and uses psychoanalytic ideas to understand the roles of museums in both the inner and outer world and the places in between. 


\title{
Object-relations in the museum: a psychosocial perspective
}

\begin{abstract}
This article theorises museum engagement from a psychosocial perspective. With the aid of selected concepts from object-relations theory, it explains how the museum visitor can establish a personal relation to museum objects, making use of them as an 'aesthetic third' to symbolise experience. Since such objects are at the same time cultural resources, interacting with them helps the individual to feel part of a shared culture. The article elaborates an example drawn from a research project that aimed to make museum collections available to people with physical and mental health problems. It draws on the work of the British psychoanalysts Donald Winnicott and Wilfred Bion to explain the salience of the concepts of object use, potential space, containment and reverie within a museum context. It also refers to the work of the contemporary psychoanalyst Christopher Bollas on how objects can become evocative for individuals both by virtue of their intrinsic qualities and by the way they are used to express personal idiom.
\end{abstract}

\section{Keywords}

Museum, object-relations, symbolisation, aesthetic third, evocative object

A young hospital patient is taking part in an experimental project to find out if interaction with a member of staff from a museum and with objects from the museum collection can help patients during their stay in hospital. She is shown some domestic objects and asked to choose one to pick up and to talk about it. She chooses a small enameled clock. This prompts a conversation about time and how perceptions of time change as people grow older. Time hangs heavy on the patients in the ward; will they grow old?

A local museum and a Children's Centre are working together in a project to help young mothers from a deprived urban area. During one visit the women are asked to identify an object to which they feel particularly drawn and to discuss in the group why they have chosen it. Some choose rare and beautiful objects from a reconstruction of a middle class drawing room; others choose more prosaic domestic items from a kitchen display. One woman in particular describes how the mixing bowl she has chosen reminds her of alternating feelings of being empty and full. This then prompts other women to talk about their experiences of motherhood. ${ }^{1}$

\section{Introduction}


This article explores how museums can enable visitors to make personally significant links with objects, and by extension with a wider cultural sphere. It draws on museological literature and psychoanalytic object-relations theory to show how the relationship established with an object can be a vital link between subjective experience, museums and wider society. It also discusses the evocative and symbolic uses of the museum object as an 'aesthetic third' for personal and social ends. The approach is in keeping with contemporary psychosocial ${ }^{2}$ theory that attempts to move beyond reductively psychological and over-social views of human subjects to understand how they relate to, and are constituted within, cultural phenomena (Bainbridge et al. 2007). Object-relations psychoanalysis is a dominant strand of psychosocial theory in which the human mind is thought to develop through interaction with a world of objects, including other people. The internalisation of those objects and of the subject's relations to them constitutes the specific patterns and emotional qualities of an individual's mental life. Museums offer particular environments in which visitors can select cultural objects of personal significance and elaborate their relations to them.

The article aligns itself with a view of museums that has moved away from 'grand foundation narratives' of museum studies (Shelton 2006, 488) to a concern with how museums are used by visitors for a range of purposes including education, enjoyment, health and well-being. They support these functions by offering opportunities for object relating. The argument has relevance for enabling facilitation within museums, especially with people who may find them culturally inaccessible.

The vignettes at the beginning are drawn from research into the UK North West regional Who Cares? programme ${ }^{3}$, which set out to promote museum engagement among people with mental and physical health problems. It asked whether and how interacting with objects in a museum can benefit health and well-being affording opportunities to learn, relax, form social relationships, make things, reminisce and so on. We discuss these briefly before presenting a case study from Who Cares? and a discussion of the potential contribution of psychoanalytic theory to museums.

\section{Museums and social practice}

A psychosocial account of museums' contribution to well-being implies that their role extends beyond preservation, knowledge and education. Museums have recently been developing a broad social practice where objects are not just purveyors of information but also of agency and affects (Gosden 2005: 196; Golding 2013). Multisensory embodied and cognitive engagement, affect and stimulation of memory are all involved (Dudley 2010; Bagnall 2003; Chatterjee 2008). Museum objects have been described as functioning as symbols of identity, relationship and social group; also of nature, society and the divine (Worts 1990; Pearce 1995). In processes of 
symbolisation, museum visitors bring to bear personal frames of reference that include emotions, memories, background and previous knowledge (Silverman 2010; Andermann and Arnold-de Simine 2012). The subjective response to museum objects and the material qualities and cultural significance of the objects are intertwined.

An approach which recognises the centrality of subjective responses to objects requires a shift away from a linear 'transmission' model of communication that posits museum staff as the 'senders' of information through exhibits and programmes to visitor 'receivers' (Silverman 2010, 15). To some extent this model has been usurped by constructivist education theory whereby museum users are understood to be actively engaged in meaning-making (Sandell 2007; Rasmussen 2002; Deeth 2012). Museum visitors encounter meanings intended by curators and educators but also create personal meanings when they connect what they find with their own lives (Silverman, 2010).

Research has revealed how museums can influence the formation of individual and social identities. For instance, Newman and McLean (2006) show how disadvantaged people used museum-based community development projects in Glasgow and Newcastle upon Tyne. Memory and reminiscence activities in which museum objects were used as memory cues enabled identity construction. Newman et al (2014) have examined how 'older' visitors can use their responses to contemporary art in art galleries for the maintenance and revision of identity. O'Neill defended the decision to include material about domestic violence in the refurbished Kelvingrove Museum in Glasgow by saying: 'People who have been victims of abuse often feel ashamed and that they do not belong. Acknowledging their experience in the museum may enable them to feel they belong in the museum...' $(2002,23)$.

The literature emphasises the interconnection of identity with memory (Mack 2003), postulating that museum objects evoke memories in ways that other informationbearing materials do not (Philips 2008). Museums have been described as 'theatres of memory' and their collections as 'containers of memory' (Mack 2003, 15). Reminiscence stimulated by museum objects is thought to affect individuals' mood, self-worth and general well-being (Arigho 2008; MLA 2008; Froggett 2011a). Bornat (2001) argues that remembering the past can build relationships among participants and help maintain identities for people facing loss and change. This article echoes some of these themes but is particularly concerned with how the capacity for attention, reflection and symbolisation may be enhanced by the process of engaging with cultural objects under the specific conditions that museums can create, and how this might include forms of receptivity that involve creative activity - writing poetry, painting and so on - as well as those that don't. 
Psychoanalysis has been influential in art history and cultural studies where literature, film, art, architecture and media are understood in terms of symbolic and unconscious representations of human desires and anxieties. However it has been little discussed in museum studies. Museums have rarely been examined in terms of the unconscious mental life of the institution and its activities of curating, collecting, conserving and educating, or of the unconscious mental life of visitors (exceptions include Trustram 2013, 2014; Lynch 2008; Clark and Phillips 2010). This article in part responds to Jordanova's comment that 'a thorough-going psychoanalytic account of museums would be fascinating' (Jordanova 1989, 40). Such an account would draw on psychoanalysis as a system of ideas about social and cultural life, examining why institutions gather into themselves thousands of objects (Obholzer 1994). It would ask how museum objects can affect a person's state of mind, and their relationships to a world of things and other people.

Museums are premised on the fact that we make relationships with objects. We use a particular strand of psychoanalytic theory, object-relations, to analyse the responses to 'evocative' cultural objects illustrated in the vignettes above. For Bollas (2009), an evocative object is one that resonates with personal and cultural significance, producing chains of association, inciting emotional responses and impelling imaginative activity. We form strong embodied connections to such objects that we 'use' according to their particular properties, entering into relationships with them that permit us to express personal idiom. In doing so we also make personal use of shared cultural resources, connecting with a cultural world that is enriched because we have endowed it with vitality. We ask how museums can facilitate such use, how active this facilitation needs to be, and what kind of environments enable it to happen? We are concerned with how this might include creative activity as well as those that don't.

First we outline key ideas from object-relations theory that illuminate the symbolic use of museum objects to mediate personal relations to a wider cultural domain. Drawing on psychoanalytical understanding of the 'third position' from which a relation between self and object can be apprehended and thought about (Britton 1998), we then consider the third space between object and subject, the space in which they meet, impact upon and form each other so that the object itself becomes a symbolic or aesthetic third (Dudley 2010, 12; Froggett et al. 2011a; Froggett et al. 2011b). By way of illustration we refer to the use of an art installation by a group of homeless men. Our discussion has implications for how museums can support staff to work with the dependent and vulnerable sides of the self that can be activated by relating to museum objects. The development of these capacities among staff becomes particularly urgent as museums extend their range of activity towards new audiences who otherwise rarely visit them and have little cultural capital. 


\section{Evocative objects and Who Cares?}

In the Who Cares? programme ${ }^{4}$, participating museums developed close working relationships with health organisations, for instance a Child and Adult Mental Health Service and the South Manchester University Hospitals Trust. Others worked with residential and day care homes, or with community-based health organisations that address specific issues like homelessness or disability discrimination. The participants were varied: from people with chronic mental ill health receiving in-patient treatment to those who were

active in their communities.

The health professionals had little experience of using museum objects and few of the museum staff had any formal therapeutic training. However most, regardless of their professional background, brought elements of the consulting room (privacy, confidentiality, clear time boundaries) into their work. Most of the projects involved engagement with objects or displays followed by facilitated creative activities. The aim was to encourage a subjective, affective engagement with objects in order to enhance self-knowledge rather than knowledge of the museum collections. This said, most of the projects had no clear theory of how the objects would affect participants, whether through their evocative or instructional qualities, or their ability to provoke thought, or enable the development of skills or simply provide enjoyment.

The projects were based in principles of creativity and care. Making things was encouraged in part because it gave participants (and policy makers and funders) tangible evidence of achievement. They reflected a common assumption that galleries full of lively, extrovert activity are doing a more effective job of engaging people than those assembled just for looking. The projects were also following constructivist education theory that argues that 'we learn best by doing', such as by making artworks or being engaged in discussion or using audio-tours (Deeth 2012, 3).

However, the opening vignettes illustrate engagement without making or doing and raise questions about the unconscious, affective dimensions of interacting with objects with or without creative activity. In exploring receptivity to museum objects we ask how the objects acquire their particular resonance. We acknowledge that creative activity may be attractive, but we are also interested in receptivity that does not involve doing or making and which in this context is under-theorised.

\section{The Who Cares? research programme}

This summary account of the research programme provides an overview of the methods and sets in context the case example that follows which is used to illustrate 
the application of object-relations theory to museums. A systematic account of the research can be found at http://clok.uclan.ac.uk/3362/.

The research project asked how museum - based activities can contribute to health and well-being and selected up to three projects from each of the six museums, ensuring a balance was maintained between those with a therapeutic, educational and craft orientation. Where a museum activity group was selected for investigation, data were collected in relation to the whole group. The methods adopted were adapted to the nature of the project, and included both participant and nonparticipant observation (recorded by video and field notes), semi-structured and narrative interviewing, focus groups and conversations in the course of creative activities (all of which were audio-recorded). The latter were particularly important in that many of the participants (for example some children and those with dementia or other forms of mental health problems) struggled with verbal self-espression and the dyadic structure of interviews. The use of an object or creative activity introduced a third entity around which an interaction could revolve.

This use of the third as a means to communicate also helped to reveal the 'thirdness' of the object (its status 'in-between' the subject who makes use of it according to her disposition and inclinations, and the cultural-symbolic order to which it is bound). In many cases the object was itself the outcome of the creative activity that facilitated engagement with the museum collections. The activities included painting, modelling, movement and singing; in five out of the six poetry was also included. The creative objects not only occasioned talk and observations, they themselves provided evidence of the engagement with, and impact of, museum - based activities. In any one project at least two, and usually three, data sources were triangulated (for example field notes, observation notes, or transcripts of recorded interviews with staff and participants). The data were subjected to hermeneutic interpretation by the research team working as a panel. In hermeneutic interpretation, hypotheses and propositions made on the basis of researchers' interpretations of the data have to find iterative support as the panel works its way through the material. Each data set was considered on its own in order to generate findings before being compared with other data sets. ${ }^{5}$

\section{Housed objects and homelessness}

Of all the groups in the Who Cares? Programme, the one of men from a homeless hostel was particularly challenging. The project in question was led by a curator who orchestrated the visit of the men to a digital installation, and afterwards provided a small room for them to work in with a performance poet, on the material they had seen. A researcher accompanied the group throughout the visit to the galleries and the subsequent poetry session, and recorded detailed observation notes. The notes 
and the co-written materials from the session with the poet were subsequently analysed by an interpretation panel.

It was impossible not to be aware that museums like the Harris in Preston, which hosted the project, are built to house precious objects whilst homeless people live nearby on the streets. In order to make them feel welcome, the men were first offered tea and sandwiches. One or two ate, drank and disappeared without giving a reason. The researcher suspected that refreshments were the main attraction. The way in which the installation was made available to those who remained was intended to elicit first 'receptive' and then 'active' engagement. The curator guided them through the galleries to the installation Recent Findings by Simon Faithfull (2010). There were three large screens. The first showed sketches of urban crows drawn on a palm pilot. The group reacted with startling hostility: the crows were "crap". The second was a black and white film of the artist doggedly following the Meridian Line on his palm pilot - along ditches, over fences and through someone's kitchen. The group was amused and curious ${ }^{6}$. The third, in colour, was a huge image of reflections in an eye, taken on Faithfull's unsuccessful trip to see the Northern Lights. Judging by their exclamations of delight, the group found it ravishing.

They then made their way through several galleries to a small, quiet, 'contained' education room. In this intimate atmosphere they co-wrote a poem with the help of a performance poet, based on what they had seen. In the poem the Meridian Line and image of the eye were woven together, drawing on personal experiences of homelessness:

Things might slow you down, keep going ...

Every paragraph is still worth knowing

Doubts disappearing through a window

Life's journey keeps on flowing through

Northern lights in my eyes

A light for every time I've tried. (Harris Museum and Art Gallery 2011)

The installation as a whole was evocative, eliciting emotionally resonant association and a poetic sensibility. It operated as a 'third' - a psychosocial pivot between personal experience and cultural meaning? ${ }^{7}$. The men were captivated by the exhibit when they started to relate it to their experience, so that the personal and the cultural became intertwined, and this happened well before they overtly did anything with it. The verse then put the experience into words, showing how their attention to the rest of the gallery had been activated. A painting of a horseman, noticed in passing, was mentioned in the final poem. Enlivened by the installation, they had spontaneously 
begun to make connections with objects from the permanent collections. During the active part of the session - the poetry writing - the men gathered up these impressions and worked them into a form that helped bind them into a group. However, the concept of the 'holding environment' (Winnicott 1965) - the physical and mental nourishment, the attentive and non-intrusive guidance and intimate space set apart for reflection - played as great a part as the facilitation of the performance poet in helping the structured verse to emerge. As the men made use of the exhibit to symbolise their own experience, their cultural reference points broadened to the political context of homelessness.

The world didn't seem to care, just like Tony Blair (Harris Museum and Art Gallery 2011)

The men's symbolic capacity was enhanced because the installation, and other objects in the galleries, became evocative and available for their use. They could make an imaginative connection between self and world that still depended on the specific nature of the object. For at least two of the men, who went on to produce a small anthology, the effect lasted beyond the session. It is tempting to speculate that the 'rejection' of the crows followed a negative association that instead of an evocative train of thought led to psychic evacuation of the "crap". Urban crows (sometimes called murder crows) are unloved avian scavengers on the streets, resented, living on refuse, sometimes aggressive. They are everywhere, without a home, and according to Faithfull (2010), they mirror the characteristics of the people among whom they live.

\section{Object-relations, health and museums}

The example above has been analysed with concepts drawn from object-relations theory. Our conception of the role of cultural experience in mental health and wellbeing draws on the work of Winnicott (1988 [1971]) and Bion (1962, 1970) who observed young children and their play, developed case studies, and in Bion's case, worked with groups. Their thinking is hermeneutic (Alvesson and Skodsgrad 2000) and reliant on theoretical plausibility whereby they argue from the specifics of cases in order to make sense of clinical material. Until recently, theory building in this tradition has involved extrapolations across cases, rather than empirical research. Researchers in the UK are now working with the concepts within psychosocial studies, including in the area of culture (Bainbridge et al. 2007). The ideas help to interpret embodied and emotional aspects of experiences. However, few so far have used them to think about the museum space and its unconscious dimensions.

Object-relations approaches in research start from an ontology of defended and conflicted subjects (Hollway and Jefferson 2000) who are not transparent to 
themselves and often cannot give an account of their experience in words. For this reason many psychoanalysts have a deep interest in the production and reception of art that expresses aspects of subjectivity that cannot be readily formulated in the linear sequences of verbal language. The hatred of the crows was a case in point "crap" seemed more like an enactment than a judgment. Although initially rather bored, the men's attention was captured by objects in the galleries that were evocative for them - the researcher observed them moving from indifference to engagement via a process of which they were largely unaware.

As conflicted subjects we encounter a reality that is only partially responsive to our desires. Whatever the men's motivations in visiting the museum, it was not as they expected or wished. However, reconciling oneself to the frustrations and gratifications of life are seen in object-relations theory as key to adequate psychosocial integration. In the men's encounter with the installation we witness first the forming of a relationship (or with the crows a refusal of relationship), then an internalisation of the experience that allows them to carry it with them to the education room where it lives in their imagination and is wrought into poetry through interaction with one another.

According to object-relations theory a store of internalised objects and relations to objects builds up for each of us during infancy and is then progressively elaborated as we go about our everyday lives. It is through living in a world of objects that we constantly test and modify that we gain a sense of our relationship to reality. By internalising a relation to these objects we become subjects with distinctive capacities for relatedness in which we can accept a world of other people and things outside of ourselves.

Object relations are imbued with emotions: love, hate and ambivalence. They pattern personal dispositions to respond to the world in particular ways. Bollas $(1992,64)$ describes this as personal 'idiom' - largely unconscious - that moves each of us through a world of objects according to particular inclinations, perceptions and judgements. Idiom is expressed through the ways in which we arrange our possessions, habits and lives, and leave a personal trace whereby others can register our imprint (Bollas 2009). "As we move through the object world, breathing our life into the impersonal, we gather and organize our personal effects" (Bollas 1992, 65). Cultural activity offers a rich arena for idiomatic expression; artists transform their material according to their distinctive idiom. In the poem the men, as a group, produced a cultural object imbued with their experience. The two who then went on to produce an anthology began to develop a style and voice in which they imprinted the poetry with their distinctive way of living the experiences that they wrote about. This sense of transforming a subjective experience so that others can share it strengthened a formerly fragile sense of connection with a cultural world. 
The men's shifting responses to the installation and then to other objects in the galleries merit further reflection. Their reactions to the three panels veered from instant emphatic repudiation of the crows, to prolonged fascination with the eye. In the process 'Recent Findings' were construed in terms of their own experience culminating in delight at the beauty of an image, in and of itself. Three different modes of symbol formation were at work. In the case of the crows the process was truncated - we speculate that this was because of a traumatic association. With the Meridian Line and the eye, the objects were attended to, incorporated and related to personal experience. Finally, in work with the facilitator, the men used inter-subjective symbolising to produce a poem. The first two phases owed little or nothing to active facilitation but the captivation and attention was made possible by the environment. The environmental conditions in which the use of an evocative object led to symbol formation, and the relational value of the cultural object then produced, can be clarified further.

\section{Holding and containing: the museum as location of cultural experience.}

Winnicott's interest in the sources of creative living led him to explore the basic conditions of creativity in the infant - mother relationship which is where he located the origins of symbolisation and of cultural experience (Winnicott 1988 [1971]). He offers an account of how the very young child in the course of individuation within the maternal environment attempts to disentangle inner conceptions from a reality that appears to be external. The infant selects 'transitional objects' that initially 'stand in' for mother when she is absent, offering the illusion of security. The transitional object can be a thumb, teddy-bear or blanket or any object that is special because it has been nominated by the infant whilst retaining an independent material existence. Winnicott saw this selection and use of the transitional object 'as if' it is mother as the first authentically creative act: an imaginative creation of the child that also exists in itself and for others. However, dealing with such complexity in a world of objects and people separate from the self is inherently anxiety provoking and the free use of transitional objects and imaginative capacity therefore requires particular conditions of holding and containing.

The functions of holding and containing are central to psychoanalytic understanding of the importance of the pre-verbal relationship between mother and infant (Wright $2009,1)$. According to object-relations theory, this creates the conditions for the development of a person's ability to symbolise psychic events. The receptive mother who holds her baby not only in her arms but also in her mind 'contains' the baby's anxiety and imparts to it the sense that the fragmented and formless sensations that it experiences from the world it inhabits can also be held in mind (Bion 1970). The infant progressively takes in the experience of being held, and of holding, from the 
receptive mother. All being well (when the holding is 'good-enough' (Winnicott 1988 [1971]), it develops its own internal containers with which fragments of sense and feeling can be bound and symbolised. The symbol is thus a third thing arising between the infant's inner experience and its apprehension of a world that appears to be 'outside' of itself. It links a subjective world to that of others through the systems of symbols (such as language) that compose the cultural order. We will return to the 'thirdness' of the symbol and of the aesthetic object presently.

The transitional object, by its very nature, is unstable and it is for the infant to cherish or test to destruction to see if it survives. Play is also reality-testing and this too requires a holding environment safeguarded by a non-intrusive mother who can emotionally 'contain' the baby's aggression and anxiety. Too much interference or imposition of mother's own conception will impinge on the child's creative agency. Winnicott is clear that in later life we recreate transitional phenomena, especially through our uses of art and culture (1988 [1971], 124; Kuhn 2013). This requires the internalised capacity for containment of the mature adult who has learned to withstand the frustration and destructiveness that inevitably accompanies processes of creative reception and production. As in infancy, the necessary condition for the creation of transitional objects in adulthood, is a non-intrusive and emotionally containing, holding environment.

It is tempting to compare elements of this account of human development with the curatorial function of a museum that both holds (looks after) objects and contains them (provides a structure that prevents their loss or decay). An equally important but often unacknowledged function is to contain the emotional responses of the museum visitor, provide the conditions for attentiveness and, for people who are ill at ease in such environments, assuage the anxiety objects may provoke. Museums also enable communities to hold certain objects collectively in mind and hence to expand the symbolic capacity of a shared culture. Of course the functions of a mother and a museum are quite different but at some level the emotions of the participants in the most successful Who Cares? projects were being 'held' by the staff within the structure of the museum itself.

In the case of the homeless men the curator's personal capacity for containment moderated her own anxiety so that she could hold onto a disparate, distracted group long enough to enable their engagement. This is different from active facilitation: it, involved an ability to communicate emotionally that the strangeness of the situation could be accommodated, so that the men felt welcome and their attention was held. This was followed by the containing function of the installation itself that was held within a frame and context that sustained attention; finally there was the protected space of the room used for the poetry. These instances of holding and containment 
supported a creative capacity to 'find' in the installation and other objects (such as the horseman) something that was already there and to endow it with personal significance. It may be that didactic facilitation intrudes on the containing function which enables visitors to discover for themselves objects that symbolise personal experience and this could do with further research. In the Who Cares? programme there were opposing views on whether participants benefitted most from instruction and a sense of achievement in making things for display, or whether a 'therapeutic' opportunity for play was more helpful.

\section{Object relating and object use}

Winnicott (1988 [1971]) made a crucial distinction between object relating, where the object is identified with, and exists in relation to and for the infant, and object use, where it is placed outside the sphere of projection so that it is perceived according to its intrinsic properties and hence allowed to live a life of its own. Because the object is selected for its properties, but at the same time endowed with personal significance, its qualities must be such that it has sufficient 'resilience' to 'resist' total assimilation by the perceiver. It can then be experienced as an object 'in itself' as well as an object 'for' the perceiver. Only then can it act back on and nourish the self, by virtue of its nature and its otherness. In the responses of the group to the three panels, and at the risk of drawing the distinctions a little sharply for heuristic purposes, we can see the difference between object relating and object use. The crows are metaphorically evacuated as "crap"; the Meridian Line is interpreted in terms of the group's own experience (object relating). The third panel also resonates with their experience but is sufficiently independent of it to elicit an intense pleasure in the image of the eye as an aesthetic object (object use). In this account of symbolisation, the cultural object is first 'incorporated' and then 'released' by the subject. In the process a form is found for personal experience that links to a cultural order that can be shared with others.

The museum objects in our two vignettes were also used by the participants to connect with a world that appeared to be outside of themselves. They made a personally distinctive use of an object, but because it was a cultural ${ }^{8}$ object this brought them into relation with a wider cultural field of which others are a part. This helped overcome a sense of separation that is particularly felt by people suffering from mental distress and isolated from normal social intercourse. It is also worth noting that the connection made with the mixing bowl, the external object in the second vignette, could not have been anticipated. Museum curators worry over whether collections are 'relevant' to particular groups of people. It is likely that people will make connections to objects in quite unpredictable ways. Indeed it is the idiomatic use of an object driven by personal inclination that provides evidence of an active capacity for symbolising, even when no particular activity designed to activate the symbolic function in participants has been provided. 


\section{The 'thirdness' of the museum object}

We are suggesting that the holding environment of the museum enables people to connect psychically with objects and so find 'external' forms for their experience. The museum object becomes a third presence within the dynamic of the individual and the groups in which they participate - an 'intersubjective third' (Froggett 2008). It is also a third presence between the individual and the cultural sphere - a 'symbolic third'. Furthermore, its availability for use (in Winnicott's sense) depends on its form and qualities and hence it is an 'aesthetic third' (Froggett et al. 2011a). It is almost certainly the conjunction of all these elements of 'thirdness' in the object that accounts for it being endowed with 'vitality', so that it resonates in the imagination. Essentially, the object that comes alive for the individual who beholds it is positioned somewhere in-between the interior world of the imagination and the external material world that contains both something of that individual (who has selected it and endowed it with personal significance) and something of the world (by virtue of its link with a cultural-symbolic order) (Dudley 2010; Froggett 2008):

It is in this link - the experience of being meaningfully conjoined with a bit of the world that mental well-being resides. The fact that the bit of the world in question is not only an object outside the self - but an object of wonder, curiosity or delight - can only enhance the pleasure in the link. The sense of discovery is not only the discovery of something new, as is often thought, it is the discovery of a personal relation to something new - an enriching expansion of relational possibilities. (Froggett et al. 2011a, 68)

\section{The museum space}

The special physical and psychic, social and personal, spaces that museums create have been explored from different disciplines. For instance Lord (2006) picks up Foucault's (1998) exposition of museums as heterotopias: real places within the culture where they are located that are set apart and where normal relations are reconceived. They are thus spaces of difference and representation. Dudley asks whether we can argue that

'...the engagements which matter happen not in objects, nor in minds nor social relationships but, physically as well as emotionally and cognitively, in the spaces in between all three?' $(2010,13)$.

When Winnicott (1988 [1971]) developed his theory of transitional phenomena and the holding environment he described the space in-between infant and (m)other (infant and world) as a 'potential space' in which the infant has the creative illusion of discovering what is there to be found; in this way a vital, imaginative and rewarding 
relation to the world is formed which impels curiosity. Winnicott asks what are we doing in adult life and where are we when, say, we make a pilgrimage to a picture gallery? He answers that we are in 'a third area of human living, one neither inside the individual nor outside in the world of shared reality' (1988 [1971], 129). This too is a potential space available for creative playing, symbolisation and the management of transitions.

The Who Cares? programme, and others like it, expand the possibilities for authentic self-expression by providing potential spaces for absorbed experience of just one or two objects. Becoming absorbed by an object means slowing down and becoming psychically part of it so that distinctions between subject and object are partially dissolved. In the alternation between immersion in the cultural object and separation from it the individual may unconsciously recapitulate earlier struggles to separate from the maternal environment and achieve an individuated sense of creativity. This is the key to developing identity and personal agency (Froggett 2001; Ehrenzweig 1967), all the while founded on a sensuous and embodied relation to a world of objects (Froggett 2006; also see Dudley 2010; Bagnall 2003; Salom 2008).

\section{Knowing, doing and being}

Museum activities that attempt to extend benefits to hitherto excluded people tend to involve doing and touching things (Lynch 2008, 268). Rees Leahy comments that Tate Modern states its current developments will "provide more places to eat, read, study, picnic, shop and just relax" (Rees Leahy 2010, 172; Prior 2006). Most museums now include greater levels of interpretation and interaction via electronic technology. Busy active galleries tend to be favoured over silent ones and it is tempting to assume that activity is the precondition of engagement. The project staff in the Who Cares? programme shared these assumptions in the design of many of the programme's projects. However, they also incorporated quiet, slow work with objects that was more akin to the conception of museums as places of silent contemplation of the intricate and special. This traditional element is, in part, museums' asset for doing health-related work. The drive to do things can be linked with anxieties about not doing and not knowing (and of course vice versa).

Within psychoanalysis the concept of 'not knowing' is important. The poet John Keats is often quoted here. Keats wrote in a letter that what distinguishes an artist like Shakespeare is a possession of negative capability, that is when a person is 'capable of being in uncertainties, mysteries, doubts without any irritable reaching after fact $\&$ reason' $(1899,277)$. Negative capability was particularly important in the work of Bion who was concerned with containment and the quality of attention it enables. Bion (1970) observed that the ability to tolerate not knowing allows the clinician to withhold imposition of their own conscious frame of reference. Negative capability is 
a precondition of open receptivity and hence attunement to the particular qualities of a person or object. According to Bion, this attunement is first experienced in the dream-like reverie with which attentive mothers hold their babies. The capacity for reverie in the cultural sphere allows the meditative contemplation of objects that are allowed to reveal themselves without being shoe-horned into the categorisations that the informational museum imposes on them. As places of learning, negative capability can be anathema to the contemporary museum caught in an active/passive binary where activity is valorised because it is seen to enable self-expression.

Besides the value of not knowing, one might consider the value of not doing. If there were less to do, maybe there would be more wondering and wandering? The danger of course is that there might also be more frustration, so that the museum is experienced as withholding for any but those who already have the resources to enjoy its collections. Visitors need interpretation in order to stimulate their receptivity, to make the link between subjective experience and the apparently objective material world. But as Dudley indicates, museum interpretation threatens to foreclose experience:

'...the object-information package can still have the power to move us, but most often it does so almost entirely through textually-provided meaning, and threatens to foreclose a more basic, but no less potent, bodily and emotional response to the material itself.' $(2010,8)$

Museum staff and psychoanalysts both offer interpretation. In museums this is the provision of information about objects on display: art museums are typically criticised for providing too little information whilst museums of history, natural science and ethnography provide more. There is also a debate within psychotherapy about when and how to interpret what the patient has said. The 'just right' interpretation is offered at a point (gauged by the felt receptiveness of the patient), and in just such a measure, that it can be used by the patient. In these circumstances the patient has the sensation of having discovered the interpretation for herself. Many museums promote themselves as places of discovery; we would suggest that a real sense of discovery can be achieved when curators provide just the right amount of information for the visitor to feel she is not being told things so much as discovering them for herself.

We find an illuminating parallel here between the creative apprehension of a cultural object in a non-intrusive museum and Winnicott's account of the development of the infant's creative capacities in the presence of the attentive but non-intrusive holding mother. Whilst creating the conditions for the infant to explore the properties of objects, she maintains a degree of distance allowing the play to emerge according to the infant's desires. If she insists on labelling and comparing the infant's activities with 
what she perceives to be reality, she will inhibit her child's ability to freely exercise his or her imagination. Winnicott identified the capacity to be 'lost' in play, and also to be alone in the presence of another, as a key to the use of potential space. The Who Cares? projects were based on the assumption that group activity can be therapeutic. It may also be that being alone in the presence of an object, at a time and place that is right for the individual, offers the possibility of developing a personally creative relation to it (Trustram 2013). We are not suggesting that the contemplative approach is more effective than the interpreted, active approach, but rather that a plurality of approaches is more likely to assist more people.

\section{Conclusion}

A psychosocial approach to museum experience led us to ask how visitors make personal use of the cultural objects that the museum holds. Our illustrations are taken from a programme in which the visitors had little experience of museums and were vulnerable and culturally excluded. We are not arguing that they present a special case, merely that the careful attentive work of Who Cares? afforded an opportunity to understand better how objects acquire an evocative character and allow people to make a link with them, endowing them with vitality so that the museum and its contents come alive and available for use. The psychoanalytic theory that has helped us conceptualise this process has been drawn from the British object-relations tradition that is concerned with how we internalise a social and cultural world and how we then transform it in idiomatic ways thus imprinting it with our character.

The objects in object-relations theory have usually been thought about in terms of relations with significant others. To the extent that inanimate objects have been considered, there has been little emphasis on the intrinsic qualities of the objects themselves as opposed to subjective relations with them. However, for the museum the intrinsic nature of the object is a vital matter of interest. Museums are not supermarkets or warehouses, they are cultural containers in a way that other institutions stuffed with objects are not. They make their collections publicly accessible for cultural rather than instrumental use or market value, implying that the specific nature of the object matters and that curatorship is the relational activity that helps to make it available. The role of the museum as conservator and educator remains important but it is carried out through its containing, relational aspect. Rather than downgrading the particular nature of the collections themselves, this perspective emphasises the particularity of objects:

To paint, dance, poeticise, or compose an experience is to select a mode of representation with its own unique aesthetic. Which mode one chooses not only results in a different mode of representation; it also suggests an entirely different experience in self-expression (Bollas 1992, 39) 
Bollas emphasises that it is not just that we use objects - they, in a sense, use us, according to their intrinsic potentials. This is the existential dimension where unconscious object relating occurs outside of processes of cognition:

... the work that characterises the unconscious ego is the nonrepresentational unconscious that selects and uses objects in order to disseminate the self into experiencings that articulate and enrich it. The aim here is not to create meanings or to interpret reality as such, but to negotiate with reality in order to gain experience of objects that release the self into being. (Bollas 1992, 42)

Finally - and this is where a psychosocial perspective rather than an emphasis on individual psychology is important - Winnicott identified the location of cultural experience as a 'third area' (1988 [1971], 102), where these self-states can be negotiated and transformed. In this essay we have identified it as the location of the 'aesthetic third', that arises within processes of symbolisation where the manner of the self's experiencing is bound to the cultural forms available to it, and expressed in symbolic systems that secure participation in a shared and communicable culture.

\section{References}

Alvesson, Mats, and Kaj Sköldberg. 2000. Reflexive Methodology. London: Sage.

Andermann, Jens and Silke Arnold-de Simine. 2012. "Introduction: Memory, Community and the New Museum." Theory, Culture and Society 29 (1): 3-13.

Arigho, Bernie. 2008. "Getting a Handle on the Past: The Use of Objects in Reminiscence Work." In Touch in Museums: Policy and Practice in Object Handling, edited by Helen J. Chatterjee, 205-212. Oxford: Berg.

Bagnall, Gaynor. 2003. "Performance and Performativity at Heritage Sites." Museum and Society 1 (2): 87-103.

Bainbridge, Caroline, Susannah Radstone, Michael Rustin and Candida Yates. 2007. Culture and the Unconscious. Basingstoke: Palgrave Macmillan.

Bion, Wilfred R. 1962. Learning from Experience. London: Maresfield.

Bion, Wilfred R. 1970. Attention and Interpretation. London: Tavistock Publications. [Reprinted London: Karnac Books 1984]. 
Bollas, Christopher. 1992. Being a Character: Psychoanalysis and Self Experience.

East Sussex: Routledge.

Bollas, Christopher. 2009. The Evocative Object World. East Sussex: Routledge.

Bornat, Joanne. 2001. "Reminiscence and Oral History: Parallel Universes or Shared Endeavour?" Ageing and Society 21: 219-241.

Britton, Ronald. 1998. Belief and Imagination. London: Routledge.

Chatterjee, Helen J., ed. 2008. Touch in Museums. Policy and Practice in Object Handling. Oxford: Berg.

Clark, Judith and Adam Phillips. 2010. The Concise History of Dress. Accessed 8 March 2014. http://www.artangel.org.uk/projects/2010/the concise dictionary of dress

Deeth, J. 2012. "Engaging Strangeness in the Art Museum: An Audience Development Strategy." Museum and Society 10 (1): 1-14.

Dudley, Sandra H. 2010. "Museum Materialities: Objects, Sense and Feeling." In Museum Materialities: Objects, Engagements, Interpretations, edited by Sandra H. Dudley, 1-17. London and New York: Routledge.

Ehrenzweig, Anton . 1967. The Hidden Order of Art. London: Paladin.

Faithfull, Simon. 2010. Recent Findings. Accessed 16 December 2013. http://www.e-flux.com/announcements/simon-faithfull-recent-findings/

Foucault, Michel. 1998. Different Spaces, trans R Hurley. In Essential Works of Foucault 1954-1984, Michel Foucault, Vol 2, 175-185. London: Penguin.

Froggett, Lynn. 2001. "From Rights to Recognition: Mental Health and Spiritual Healing Among Older Pakistanis." Psychoanalytic Studies 3 (2): 177-186.

Froggett, Lynn. 2006. "Thinking With the Body: Artistic Perception and Critical Reflection". In Critical Reflection in Health and Social Care, edited by Sue White, Jan Fook and Fiona Gardner, 89-106. Maidenhead: McGraw-Hill Education, Open University Press. 
Froggett, Lynn. 2008. "Artistic Output as Intersubjective Third." In Object Relations and Social Relations: The Implications of the Relational Turn in Psychoanalysis, edited by Simon Clarke, Herbert Hahn and Paul Hoggett, 87-111. London: Karnac.

Froggett, Lynn, Alan Farrier, Konstantina Poursanidou and Suzanne Hacking. 2011a. Who Cares? Museums and Social Engagement. Psychosocial Research Unit: University of Central Lancashire. Accessed 17 February 2013. http://clok.uclan.ac.uk/3362/

Froggett, Lynn, Alastair Roy, Robert Little and Leah Whitaker. 2011b New Model Arts Institutions and Public Engagement Final Report, Psychosocial Research Unit: University of Central Lancashire. Accessed 17 February 2013. http://www.uclan.ac.uk/schools/school of social work/research/pru/files/wzw nm i report.pdf

Golding, Viv. 2013. "Museums, Poetics and Affect." feminist review 104: 80-99.

Gosden, Chris. 2005 "What do Objects Want?" Journal of Archaeological Method and Theory 12: 193-211.

Harris Museum and Art Gallery. 2011. Hold Onto Life. Preston: The Harris Museum.

Hollway, Wendy and Jefferson, Tony. 2000. Doing Qualitative Research Differently. London: Sage.

Jordanova, Ludmilla. 1989. "Objects of Knowledge: A Historical Perspective on Museums." In The New Museology edited by Peter Vergo, 22-40. London: Reaktion Books.

Keats, John. 1899. The Complete Poetical Works and Letters of John Keats. Cambridge: Houghton, Mifflin and Company.

Kuhn, Annette, ed. 2013. Little Madnesses: Winnicott, Transitional Phenomena and Cultural Experience. London: I B Tauris.

Lord, Beth. 2006. "Foucault's Museum: Difference, Representation and Genealogy." Museum and Society 4 (1): 1-14.

Lynch, Bernadette. 2008. "The Amenable Object: Working with Diaspora Communities through a Psychoanalysis of Touch." In Touch in Museums, edited by Helen J Chatterjee, 261-272. Oxford: Berg. 
Mack, John. 2003. The Museum of the Mind: Art and Memory in World Cultures. London: The British Museum.

MLA. 2008. Outcomes Framework for Museums. London: Museums, Libraries and Archives Council.

Newman, Andrew and Fiona McLean. 2006. "The Impact of Museums upon Identity." International Journal of Heritage Studies 12 (1): 49-68.

Newman, Andrew, Anna Goulding and Chris Whitehead. 2014. "Contemporary Visual Art and the Construction of Identity: Maintenance and Revision Processes in Older Adults". International Journal of Heritage Studies 20 (4): 432-453.

Obholzer, Anton. 1994. The Unconscious at Work: Individual and Organizational Stress in the Human Services. London: Routledge.

O’Neill, Mark. September 2002. "Beauty and the Beast." Museums Journal: 21 - 23.

Pearce, Susan M. 1995. On Collecting: An Investigation into Collecting in the European Tradition. London and New York: Routledge.

Philips, Laura. 2008. "Reminiscence: Recent Work at the British Museum." In Touch in Museums, edited by Helen J Chatterjee, 199-204. Oxford: Berg.

Prior, Nick. 2006. "Postmodern Restructurings." In Companion to Museum Studies, edited by Sharon Macdonald, 509-524. Oxford: Blackwell.

Rasmussen, Susan. 2002. "The Uses of Memory." Culture and Psychology 8 (1): 11329.

Rees Leahy, Helen. 2010. "Watch Your Step: Embodiment and Encounter at Tate Modern." In Museum Materialities, edited by Sandra Dudley, 162-174. London: Routledge.

Salom, Andree. 2008. "The Therapeutic Potentials of a Museum Visit." International Journal of Transpersonal Studies 27: 1-6.

Sandell, Richard. 2007. Museums, Prejudice and the Reframing of Difference. London and New York: Routledge. 
Shelton, Antony. 2006. "Museums and Museum Displays." In Handbook of Material Culture, edited by Christopher Tilley, Webb Keane, Susanne Kuchler, Mike Rowlands and Patricia Spyer, 480-499. London: Sage.

Silverman, L. H. 1990. Of Us and Other Things: The Content and Functions of Talk by Adult Visitor Pairs in an Art and a History Museum. Unpublished doctoral dissertation, University of Pennsylvania: Philadelphia.

Silverman, L. H. 2010. The Social Work of Museums. London: Routledge

Trustram, Myna. 2013. "Little Madnesses of Museums." In Little Madnesses: Winnicott, Transitional Phenomena and Cultural Experience, edited by Annette Kuhn, 187-203. London: I B Tauris.

Trustram, Myna. 2014. "Asylum and the Museum." American Imago 71 (1): 67-84.

Winnicott, D. W. 1965. The Maturational Process and the Facilitating Environment: Studies in the Theory of Emotional Development. London: Hogarth Press and the Institute of Psychoanalysis.

Winnicott, D. W. 1988 [1971]. Playing and Reality. London: Pelican.

Worts, D. 1990. "In Search of Meaning: 'Reflective Practice' and Museums." Museum Quarterly 18 (4): 9-20.

Wright, Kenneth. 2009. Mirroring and Attunement. Self-realization in Psychoanalysis and Art. East Sussex: Routledge.

\footnotetext{
${ }^{1}$ These vignettes are based on empirical projects evaluated or researched by the authors. They serve to bring to the mind of the reader the kind of experience we are writing about and we refer back to them as illustrative of one of the key points of the article.

${ }^{2}$ The website of The Association for Psychosocial Studies provides an introduction to this field of academic enquiry: http://www.psychosocial-studies-association.org

${ }^{3}$ The research report is available at http://clok.uclan.ac.uk/3362/. It was undertaken by the Psychosocial Research Unit at the University of Central Lancashire with the collaboration of the museums. Thanks are due to Alan Farrier, Konstantina Poursanidou and Suzanne Hacking for their contributions. Examples from the project will be used by way of illustration only since our purpose is to explore the value of object-relations theory to museums.
} 
${ }^{4}$ The museums (Manchester Art Gallery, Manchester Museum, Whitworth Art Gallery, Harris Museum and Art Gallery, Bolton Museum and Archive Service, Tullie House Museum and Art Gallery) were all members of the North West Renaissance Hub that was set up by the Renaissance in the Regions programme in 2005. The collaboration of the project leaders was essential to the research and their contribution is acknowledged with gratitude.

${ }^{5}$ Approval for the research was granted by the regional National Health Service ethics committee, after full ethical review. All invitations to join groups were subject to approved conventions. Informed consent and confidentiality were assured subject to the constraints of group-based activities. Given the vulnerable nature of some of the participants, appropriate support and de-briefing were assured in all cases, if they were required. The research process was overseen by a steering group composed of representatives from each of the museums that met at three monthly intervals.

${ }^{6}$ The observation of affect, in the absence of interview-based confirmation, presupposes the ethnographer's ability to correctly interpret behavioural signals (laughter indicates amusement, curiosity leads to continued questioning and so on). The interpretation is then triangulated with further data, in this case from the poetry writing session where amusement and curiosity were also expressed.

${ }^{7}$ Although personal experience and cultural meaning are always in part mutually constitutive, a psychosocial perspective would hold that elements of personal experience are biographical, dispositional, embodied and non-discursive. Experience cannot be assimilated to meaning or vice versa, the two are always in tension.

${ }^{8}$ We use the term 'cultural object' in a loose Winnicottian sense as something that is part of 'the inherited tradition ... the common pool of humanity' (1988 [1971], 116). 